\title{
Not All Those Who Wander are Lost: Examining the Character Strengths of Dyslexia
}

\author{
Chathurika Kannangara*, Jerome Carson, Sowmya Puttaraju and Rosie Allen \\ Education and Psychology, University of Bolton, England
}

Submission: May 25, 2018; Published: July 18, 2018

*Corresponding author: Chathurika Kannangara, Education and Psychology, University of Bolton, England. Email: C.Kannangara@bolton.ac.uk

\begin{abstract}
The number of students and people with dyslexia and other learning differences has been steadily increasing in recent years. This has led to an accompanying need for additional support for people with dyslexia. Whilst acknowledging that support is vital for people with dyslexia, it is also important to identify the strengths that people with dyslexia have that help individuals flourish. For many years, dyslexia research has been more pre-occupied in exploring the problems faced by people with dyslexia. This study attempts to explore the strengths of people with dyslexia. This quantitative study looked at 89 people with dyslexia [ $\mathrm{N}=89$ ] from the UK and USA. Using the Values in Actions Character Strengths Inventory, participants were given the opportunity to explore their signature strengths. The survey was hosted on a specially designed Dyslexia friendly website. The length of the survey at 240 questions may have proved a deterrent for some respondents, many of who gave up half way through. From the results of those who completed the survey the main signature strengths for people with dyslexia are, Curiosity, Fairness, Kindness, Judgement, Honesty, Leadership and Humour. Comparisons were made between the sample of people with dyslexia and with wider general population surveys. Addressing the strengths of people with dyslexia is as important as looking at their problems and difficulties. The authors feel there is a need for a shorter measure of character strengths that could be used in future research.
\end{abstract}

Keywords: Dyslexia; Learning disability; Word blindness; Psychology; High-Level Reasoning; Visual spatial Abilities; Spelling difficulties; Memory; Problem Solving; Creativity; Interpersonal Strengths; Determination; Resilience; Perceptions; Environmental sensitivity; Curiosity; Pictorial thinking; Intuition

\section{Introduction}

Traditionally, dyslexia was considered as a learning disability that encompassed an array of reading and writing difficulties. Initially understood as "word blindness", dyslexia is fundamentally a visual processing deficit that impacts on an individual's literacy skills. In recent decades, and coinciding with the rise of positive psychology, learning disabilities such as dyslexia have been examined by an alternative approach. Instead of perceiving dyslexia as an inability for specific literacy skills; researchers and authors have begun to identify areas in which dyslexia individuals thrive, flourish and actually outperform typical readers. By identifying the strengths that accompany dyslexia, this replenishes the self-belief and confidence in individuals who have mostly been failed by the educational system. More recently, this has been acknowledged, and a start has been made in addressing dyslexia in childhood by adopting different teaching strategies in educational institutions to account for their different approach to learning and their specific needs [1]. In 2008, significant differences in the strengths profiles of individuals with and without dyslexia were demonstrated [2]. Since, research into dyslexia has further enhanced our understanding and identified several strengths and character strengths that are associated with dyslexia.

\section{High-Level Reasoning and Visual-spatial Abilities}

Research has demonstrated that individuals with dyslexia have particularly high-level reasoning that consists of superior mental reasoning, interconnected reasoning, narrative reasoning and dynamic reasoning [3]. Numerous studies led researchers and authors to reach this conclusion. Indeed, it was revealed that dyslexic students were consistently more accurate in processing multi-perspective 3-D information than non-dyslexic students. Dyslexic adolescents excelled in virtual reality tasks when asked to reconstruct a 3-D house from memory, when compared to adolescents who did not have dyslexia [4]. An early piece of research that was conducted over 30 years ago noticed that dyslexic children share a passion for tasks that involve spatial activities, such as drawing, doing mechanical puzzles and building models [5]. This highlights the great potential of dyslexic individuals in areas where this ability or strength has real world value, such as 3-D spatial awareness in architecture, construction, mechanics, interior design, art and design.

Considering previous research, it can be concluded that individuals with dyslexia have an enhanced ability to process visual-spatial information holistically as opposed to part by part [6]. Furthermore, research has found a strong association 


\section{Global Journal of Intellectual \& Developmental Disabilities}

between dyslexia and the speed of recognition of impossible figures, which is also a visual-spatial task [6]. There is a link between dyslexia and visual processing as research has suggested that there are neurological advantages accompanied with dyslexia that are hugely beneficial in fields such as astronomy [7]. If individuals with dyslexia have a passion for visual-spatial activities and excel in such activities, then it would be assumed that these individuals pursue careers that are based around these superior abilities. Correspondingly, the incidence of dyslexic students enrolling in courses surrounding the creative arts (art and design, photography, engineering, graphic design etc.) is increasingly higher as opposed to courses such as economics and law $[8,9]$. In light of this, it was also found that the vast majority of architects working at an architect's firm experienced spelling difficulties [10] and there are many dyslexic individuals working in the design industry [11].

Strengths in narrative reasoning mean that drawing from episodic or personal memory is the preferred method of memory storage for individuals with dyslexia. Indeed, they tend to think in a highly creative, narrative, thinking style that allows them to excel in learning and remembering when they do so by transforming abstract information into narrative information through stories etc. Consequently, creative writing is somewhat of a joy for many dyslexic adults, despite the difficulties they encounter with academic writing [3]. Additionally, dyslexia provides strengths in dynamic reasoning which involves recognising patterns in the real world. Individuals with excellent dynamic reasoning tend to excel in tasks perceived as difficult or confusing by non-dyslexics [3]. When comparing the visual-spatial abilities of dyslexic and non-dyslexic college students, it was revealed that those with dyslexia were better at memorising blurry looking images that resembled $x$-ray images. Furthermore, it was suggested that individuals with dyslexia may show an advantage in science or medicine specific roles due to their enhanced perception and memory for low spatial frequency components, compared to typical readers [12].

Research has proposed that the profound visual abilities that are associated with dyslexia may be a result of brain structure. Such that, it was found that there are specific changes that occur in the brain when reading skills are acquired. Indeed, as illiterate adults began to develop reading skills, they also began to lose their former abilities in visual-spatial tasks. Henceforth, it was posited that the visual-spatial abilities that accompany dyslexia are an object of poor reading capabilities [13]. Individuals with dyslexia may exhibit excellent visual-related abilities as a result of their inability to sustain visual attention [14]. However, the lack of talent in reading - due to a loss of focus and attention can lead to talents in other areas. For instance, previous research has identified that dyslexic individuals would be increasingly helpful and excel in particular job prospects that involve being alert to a lot of information at once, finding anomalies and are sensitive to environmental changes, such as security. It has also been demonstrated that individuals with dyslexia can distribute their attention in a much broader fashion. Subsequently, research has shown that dyslexic adults were increasingly more talented at using their peripheral vision in visual tasks [15]. Much later, Geiger and colleagues further investigated this concept and revealed that individuals with dyslexia also outperformed nondyslexic adults when asked to recall words spoken at a party, as they could identify voices more widely-distributed in the room [16].

\section{Memory and Problem Solving}

Individuals with dyslexia have certain superior cognitive abilities that mean they outperform typically developing individuals in recognition memory tasks [17]. Authors Dr Brock L. Eide and Dr Fernette F. Eide published a book called "The Dyslexic Advantage" in 2011 that argued dyslexic individuals are highly creative, perceptive, interdisciplinary and recombinatory. This aids individuals with dyslexia to organise and manipulate information that is apparently suited to processing big picture connections as opposed to finer details. Indeed, research has posited that dyslexic individuals have a heightened capability to identify distant and unusual connections. For instance, when asked to describe similarities between two objects, dyslexic individuals strayed from obvious connections and rather pointed out more "out of the box" connections [3]. Individuals with dyslexia are more likely to recognise the wider-picture of a problem, idea or message as opposed to focusing on the finer details. By acknowledging the overall context, dyslexic people have been shown to display a "gist detection" that enables them to understand the wider meaning or background of an idea, message or event [18].

Henceforth, this coincides with the distinguished problem solving capabilities that are seen in so many dyslexic individuals. In solving problems, individuals with dyslexia prove talented in adopting an interdisciplinary approach as opposed to taking a more reductive approach. This means that dyslexia individuals use numerous approaches when solving problems by altering their techniques and applying them in new and different ways.

\section{Creativity}

In closer inspection of previous research, there is much overlap between the identified strengths and positives that accompany dyslexia and the core virtues and character strengths that were classified by Peterson \& Seligman in 2004. In addition to this, research demonstrates how influential using character strengths are for personal well-being [19-21].

In examining the visual-spatial creativity of dyslexic students, compared to non-dyslexic students, research has revealed that individuals with dyslexia were exceedingly more creative and produced more alternative possibilities in a picture production activity [9]. Research into dyslexia has also proposed that while children with developmental dyslexia showed poor reading and verbal memory abilities, they outperformed typically developing children in visual memory and creativity tasks [22]. A strong link between dyslexia and creativity has been established 
[23,24]; Wolfe [8]. Moreover, during drawing tasks, children with developmental dyslexia consistently showed a faster performance and it was reported that their drawing had greater detail [25]. Also, 6 high school students with dyslexia were significantly more successful in a creativity task that required them to connect an unusual combination of ideas [26]. This is also suggested by the "slow reading, fast thinking" abilities that accompany dyslexic individuals [27].

In acknowledging the need for research that investigated the positive attributes that come from have a learning disability such as dyslexia, its links to creativity instil hope and reassurance to individuals with dyslexia. Through publishing her book "Creative, Successful, Dyslexic", interviews with numerous successful individuals with dyslexia and their personal experiences and struggles were revealed. Further, Rooke (2016) points out the strengths behind dyslexia, while indicating the profound creativity behind their success stories [28]. Individuals with dyslexia tend to be more creative and artistic due to the concentrated activation in the right hemisphere of the brain. It is also argued that career paths that allow the expression of this creativity will enhance the development of identity in individuals with dyslexia [29]. Creativity is one of the core strengths of dyslexia and is closely associated with life satisfaction. Thus, by optimising the strengths of dyslexic individuals, it is possible to enhance the overall psychological well-being of individuals with dyslexia [30].

\section{Interpersonal Strengths}

In addition to creativity and cognitive advantages, dyslexic adults are consistently more successful and talented at networking and team work [31]. Additionally, teachers with dyslexia are more likely to stress the importance of empathy and understanding in teaching and highlights how teachers with dyslexia use their strengths to overcome the difficulties they face [32]. Furthermore, student teachers with dyslexia stressed the importance of being listened to and indicated how important it is for environmental factors to facilitate their specific needs [33]. This further highlights the empathetic nature of student teachers with dyslexia and again reinforces the kind nature of individuals with dyslexia. Individuals with dyslexia are not only more empathic and kind, but it was revealed that dyslexic student nurses were less likely to drop out [34]. Henceforth, by taking advantage of their strengths, dyslexic individuals can excel in teaching (Burrows \& Wolf (1983)) [32] and training [35]. This is further reinforced as the recent research into dyslexic strengths has identified several core strengths that closely align with the positive model proposed by Vail [36] over 25 years ago. It was revealed that individuals with dyslexia outperform non-dyslexic individuals in curiosity, empathy, energy, divergent thinking and exceptional memory.

\section{Determination and Resilience}

As dyslexia is a condition that is characterised by difficulties in reading and writing, there are an abundance of psychological issues that are reported in some people with dyslexia, including depression, low self-esteem, attentional problems and reduced self-efficacy. However, research revealed that while individuals with dyslexia are greatly impacted by academic and psychological struggles due to their condition, their levels of resilience are not affected. Rather, individuals with dyslexia are equally, if not more resilient than non-dyslexic individuals [37].

It was found through qualitative research, that trainee teachers with dyslexia were particularly resilient in their pursuit of becoming primary school teachers. They experienced negativity themselves as children, with the negative attitude of teachers having a detrimental effect on their self-esteem and confidence. Regardless, the trainee teachers strived towards their goals despite the negativity they faced, with help from more positive role models. According to the trainee teachers with dyslexia, these positive teachers greatly improved their educational experiences and acted as a role model, further inspiring them to become teachers themselves [38].

There are a great number of learning difficulties that are accompanied with reading and writing difficulties. Individuals with learning difficulties tend to choose less demanding courses of education [39]; produce lower graduation rates [40] and present indicators of social alienation, lower employment rates and less earnings [41]. However, it has been shown that dyslexia specifically, does not affect an individual's abilities to work effectively at the highest occupational level [42].

\section{Supporting Theories}

Through in-depth interviews with successful dyslexic adults, three themes were extracted that categorised the strengths of dyslexic adults. First, work strengths identified by dyslexic adults are determination and resilience. Cognitive strengths are big-picture approaches and creativity; while interpersonal strengths are team work and empathy Agahi \& Nicolson (2012). To reinforce the success of dyslexic adults, Julie Logan (2009) identified the high incidence of dyslexia in successful entrepreneurs. Following the identification of a high incidence of dyslexia in successful entrepreneurs [43], further investigation proceeded. That is, research found that there are entrepreneurspecific strengths that strongly relate to the abilities of dyslexic adults. While they share the strengths of dyslexic adults in study 1 Agahi \& Nicolson (2012) there are entrepreneur-specific skills such as vision, communication, proactivity and freedom (Sepulveda, Agahi \& Nicolson, 2012). This gains support from research that has highlighted the major success of dyslexic individuals as business professionals [44], health professionals [45], school teachers [46] and post graduate students and university lecturers [47].

Davis and Braun (1987) proposed "eight gifts" of dyslexia, which were: the ability to alter and create perceptions; environmental sensitivity; curiosity; pictorial thinking; intuition and insight; multidimensional thought and perception; experience thought as reality; and vivid imagination. They argued 
that if these basic abilities are not suppressed or destroyed in early childhood, then over-average IQ and excellent creative abilities will occur. More recently, a successful dyslexic author commented that dyslexic individuals are more suitably equipped by strengths and abilities relevant for future technologies [48]. He argues that the visual-spatial talents of dyslexia make them better at understanding the complexity of new technologies [48]. In further support of this, dyslexics are naturally dominant in using their right-brain abilities which means they are invaluable to the future technologically advanced society [49]. Finally, a literature review proposes that strengths of dyslexia include high level reasoning, critical thinking skills, excellent problem solving skills, deep approached to learning, lateral thinking, determination and resilience [50].

\section{Coping with Dyslexia}

Qualitative research has demonstrated that individuals with dyslexia utilise numerous coping strategies in managing the challenges and difficulties they face as a result of their dyslexia $[51,52]$. Correspondingly, it would be a worthwhile pursuit to support individuals with dyslexia to change their attribution style from pessimistic to optimistic [53]. There are significant differences in learning strategies and approaches to studying between students with and without dyslexia. Furthermore, research indicates that students with dyslexia utilised study aids and time management strategies compared to students without dyslexia - who focused on selecting main ideas and test taking strategies [54]. Moreover, dyslexic students adopt a deeper approach to learning.

Ultimately, individuals with dyslexia possess an array of strengths and character strengths that can be focused and built upon to optimise the use of their skill-set, which in turn, will enhance their psychological well-being and success. Dyslexia is accompanied with strengths in high-level reasoning; visualspatial abilities; superior cognitive abilities such as problem solving and memory; resilience and determination; creativity; empathy; communication and interpersonal skills; leadership and teamwork. Correspondingly, individuals with dyslexia have thrived and flourished in careers that involve the strengths associated with dyslexia, which allows them to express their strengths in a more creative way, such as: architecture, engineering, construction, art and design, interior design, astronomy, security, medicine, science, photography, media, fashion, business management, invention and entrepreneurial positions.

While dyslexia is associated with so many positive attributes and incredibly useful and beneficial strengths for employment and success in modern society; the educational system has strayed behind in its attempt to facilitate this. Not only do individuals with learning disabilities experience great stress, anxiety, depression and other psychological struggles; but they also face difficulties in the preparation for higher study. The lack of information given regarding their pursuit of higher education, as reported by a cohort of students with learning disabilities, could explain the low incidence of students with learning disabilities in higher education [55]. Moreover, the negative experiences of dyslexic children, due to conventional teaching methods and an educational program catered to typical readers, has produced a community of dyslexia individuals with low selfesteem, depression and low confidence in their abilities.

There is clearly a need for positive interventions and an early detection of dyslexia in children, to guide individuals with dyslexia into strengths-orientated development from an early age. By changing the educational system and their approach to dealing with children with underdeveloped or limited literacy skills, this will allow dyslexic children - as well as children with other learning difficulties - to flourish and be inspired to pursue passions and interests of their that is tailored to their own personal strengths and skill set.

\section{Present Study}

Reinforcing a strengths approach to dyslexia is a worthwhile pursuit for psychological and educational research and practice. Cultivating a sense of personal well-being is one of the main aims of positive psychology and character strengths is one of the pillar which strengthens individual well-being and happiness [19]. Identifying the character strengths and virtues of people with dyslexia can help them make the most of their abilities $[20,56]$. Subsequently, the present study aims to further investigate the empirical evidences to support a strengths-based approach to dyslexia. In utilising the Values In Action Character Strengths Inventory [VIA] to understand the character strengths and virtues that are prominent among dyslexic individuals. The inventory enables the exploration of individual strengths with the most significant strengths determining the individual's character. While this inventory was originally used to examine character and strength differences between different countries and cultures; the present study applies the strengths inventory to a sample of individuals with dyslexia. Through an exploration of the top 5 signature strengths, the present study aims to identify the common character strengths of dyslexia.

\section{Study 1}

Study 1 aims to build upon already existing research into the strengths of dyslexia, by further examining the character strengths that are observed in so many cases of dyslexia. Furthermore, this study aims to utilise the VIA to better understand common character strengths of dyslexia.

\section{Participants and Procedure}

A total of 89 dyslexia adults participated in the present study. Participants were recruited on a voluntary basis and all self-declared having dyslexia. First participants were required to give basic demographic information including: age, nationality and education level. Participants were then asked to complete the VIA-IS on the VIA website. Some participants also provided a statement about their experience of exploring their character 


\section{Global Journal of Intellectual \& Developmental Disabilities}

strengths using the VIA-IS and these statements will be briefly discussed in the discussion section.

\section{Measure}

For this study, the 240-item version of the VIA-IS [20,21] was used. Measuring the responses to the 240 items generates insight into 24 character strengths that are considered universal. Each of the 24 character strengths were measured by 10 items, which are measured using a five point Likert scale - with one being "very much unlike me" and 5 being "very much like me"]. Scoring for each character strength had a range from 10 to 50 , whereby the higher the score indicating a higher endorsement of the relevant strength. With permission and support from the VIA Character Institute, a dyslexia user friendly format website was developed in order to launch the VIA-IS for people with dyslexia. Indeed, the website www.desireabledyslexia.com was enabled with functions such as adjusting font size, background colour, font style and audio options which could enable participants to listen to questions as opposed to reading them.

\section{Results}

Using the VIA-IS with a sample of dyslexic adults identified the most and least common character strengths of dyslexia. Scores are expressed as mean score per item, with Table 1 presenting the 24-character strengths of the VIA-IS in descending order. The most common character strengths shared among dyslexia adults were: curiosity [3.98], fairness [3.96], kindness [3.94], judgement [3.85], honesty [3.83] and leadership [3.77] while the least common character strengths among the dyslexic sample were zest [3.57], prudence [3.51], perseverance [3.50], humility [3.49], hope [3.47], self-regulation [3.21] and spirituality [3.15]. The top five and bottom five-character strengths have been highlighted (Table 2).

Table 1: Dyslexia Signature Strengths in Comparison to UK and USA Strengths Profiles of the study conducted by Park, Peterson \& Seligman [60].

\begin{tabular}{|c|c|c|c|}
\hline Character Strength & Dyslexia Rank (Mean) $(\mathrm{N}=89)$ & USA Rank (Mean) & UK Rank (Mean) \\
\hline Curiosity & $1(3.98)$ & $3(3.99)$ & $3(3.90)$ \\
\hline Fairness & $2(3.96)$ & $1(4.00)$ & $2(3.92$ \\
\hline Kindness & $3(3.94)$ & $5(3.96)$ & $5(3.82)$ \\
\hline Judgement & $4(3.85)$ & $2(3.99)$ & $1(3.91)$ \\
\hline Honesty & $5(3.83)$ & $4(3.97)$ & $6(3.77)$ \\
\hline Leadership & $6(3.77)$ & $14(3.74)$ & $10(3.65)$ \\
\hline Humour & $7(3.75)$ & $9(3.82)$ & $11(3.64)$ \\
\hline Creativity & $8(3.74)$ & $11(3.77)$ & $8(3.69)$ \\
\hline Forgiveness & $9(3.70)$ & $17(3.65)$ & $16(3.54)$ \\
\hline Love of Learning & $10(3.68)$ & $8(3.89)$ & $4(3.87)$ \\
\hline Teamwork & $11(3.68)$ & $15(3.66)$ & $17(3.51)$ \\
\hline $\begin{array}{l}\text { Appreciation of Beauty and } \\
\text { Excellence }\end{array}$ & $12(3.64)$ & $10(3.82)$ & $9(3.67)$ \\
\hline Perspective & $13(3.64)$ & $12(3.77)$ & $13(3.61)$ \\
\hline Gratitude & $14(3.63)$ & $6(3.96)$ & $14(3.59)$ \\
\hline Love & $15(3.63)$ & 7 (3.91) & 7 (3.71) \\
\hline Social Intelligence & $16(3.61)$ & $13(3.75)$ & $12(3.63)$ \\
\hline Bravery & $17(3.60)$ & $16(3.65)$ & $15(3.54)$ \\
\hline Zest & $18(3.57)$ & $21(3.57)$ & $19(3.37)$ \\
\hline Prudence & $19(3.51)$ & $22(3.50)$ & $21(3.30)$ \\
\hline Perseverance & $20(3.50)$ & $18(3.62)$ & $18(3.41)$ \\
\hline Humility & $21(3.49)$ & $23(3.40)$ & $22(3.21)$ \\
\hline Hope & $22(3.47)$ & $19(3.60)$ & $20(3.33)$ \\
\hline Self-regulation & $23(3.21)$ & $24(3.27)$ & $21(3.17)$ \\
\hline Spirituality & $24(3.15)$ & $21(3.53)$ & $24(2.87)$ \\
\hline
\end{tabular}

Park, Peterson and Seligman [57] revealed the signature strengths of the UK and USA general population, and the present study aimed to further analyse the present findings by

comparing these findings to the signature strengths of dyslexic adults. As identified in Table 2. 


\section{Global Journal of Intellectual \& Developmental Disabilities}

Table 2: Dyslexia strengths profile 24-character strengths in descending order for 89 dyslexic adults.

\begin{tabular}{|c|c|}
\hline Character Strength & Rank Order (Mean Score) \\
\hline Curiosity & 3.983 \\
\hline Fairness & 3.963 \\
\hline Kindness & 3.944 \\
\hline Judgement & 3.846 \\
\hline Honesty & 3.831 \\
\hline Leadership & 3.772 \\
\hline Humour & 3.749 \\
\hline Creativity & 3.735 \\
\hline Forgiveness & 3.704 \\
\hline Love of Learning & 3.682 \\
\hline Teamwork & 3.682 \\
\hline $\begin{array}{l}\text { Appreciation of Beauty and } \\
\text { Excellence }\end{array}$ & 3.642 \\
\hline Perspective & 3.636 \\
\hline Gratitude & 3.633 \\
\hline Love & 3.63 \\
\hline Social Intelligence & 3.612 \\
\hline Bravery & 3.601 \\
\hline Zest & 3.567 \\
\hline Prudence & 3.509 \\
\hline Perseverance & 3.504 \\
\hline Humility & 3.49 \\
\hline Hope & 3.47 \\
\hline Self-regulation & 3.212 \\
\hline Spirituality & 3.153 \\
\hline
\end{tabular}

\section{Discussion}

The dyslexia sample in the present study demonstrated a set of common character strengths as well as some less common strengths. The most common dyslexia signature strengths were; Curiosity, Fairness, Kindness, Judgement, Honesty, Leadership and Humour. Among these strengths, two of them (Judgement and Curiosity) belong to the Wisdom and Knowledge virtue, next two (Fairness and Leadership) belong to Justice virtue, one (Kindness) from Humanity, one (Honesty) from the Courage virtue and humour from transcendence virtue [20]. These findings also indicate that wisdom and knowledge and justice are core virtues, seen more commonly among people with dyslexia. These findings support the arguments of "slow reading fast thinking" abilities among people with dyslexia [27]. The comparison of the dyslexia sample with the previously identified strengths profiles of general population samples from the US and UK, shows that people with dyslexia excel in curiosity compared to the general populations of UK and USA, also Fairness is a core strength across all populations. However, kindness is the second most common strength amongst the dyslexia sample. One of the most significant differences between the three populations are that Leadership is one of the key strengths on the top list for dyslexia whereas for general populations at $14^{\text {th }}$ and $10^{\text {th }}$ positions in two countries. This explains the arguments about successful dyslexic entrepreneurs Sepulveda, Agahi \& Nicolson (2012) [44].

Similarly, the least common strengths among people with dyslexia match with the general population samples from the US and UK [57]. Hence these findings indicate that there are number of similarities in strengths profiles considering the most common strengths and the least common strengths. There was a contrast with 'Love of Learning'. For the dyslexia sample, this strength scored at the 10th position whereas for the UK general population sample, the mean score was at fourth and in the US it was at eighth. This indicates that the dyslexia sample's rating was way below both of these samples. For people with dyslexia love of learning may be associated with their challenges linked to reading and writing [58].

After completing the inventory some participants were invited to explain their experience of taking part in the strengths exploring activity. Those who replied with a statement of their experience explained how they relate their strengths to their character. Some also specified that some of the strengths identified were typical for them and that this confirmed their understanding about themselves. Participants felt that they had some unique character strengths within them. These findings indicate the necessity of highlighting strengths among people with dyslexia as well as among any group.

General dyslexia definitions International Dyslexia Association (2002), and discussions on dyslexia, do not provide emphasis on the strengths profiles of people with dyslexia. Rather they focus more on weaknesses. In contrast to these findings, Everatt, Weeks, and Brooks [2] identified a significant difference in the strengths profiles of people with dyslexia and other learning difficulties, compared to a control group of students without these conditions.

Having identified a number of common strengths among people with dyslexia, it would be useful to adopt strengths based approaches for intervention and for education. In order to promote a positive sense of self and positive wellbeing among people with dyslexia, strengths exploration exercises and strengths-based interventions can be applied [59,60]. Previous research has demonstrated that some character strengths are robustly associated with life satisfaction. Curiosity is one of the strengths associated with life satisfaction [20]. It is also a signature strength for people with dyslexia. Using character strengths in daily life also enhances wellbeing [19-21]. This indicates that applications of strengths in daily life among people with dyslexia, will increase their life satisfaction and enhance their overall wellbeing. These research findings support strengths based interventions and approaches for people with dyslexia.

There are some limitations with the present study that need to be highlighted. The VIA-IS has 240 questions which we hosted 
in a dyslexia user-friendly website. Despite this, the length of the survey was a major limitation. This was also seen in the number of participants who started the survey, but failed to complete it. People with dyslexia tended to drop out after completing about 50 to 100 questions. This indicates that a shorter version of this survey might be more beneficial in assess strengths among people with dyslexia and other learning difficulties. A brief character strengths inventory was validated for China and Hong Kong has been developed by Professor Samuel Ho and his colleagues. The brief version consists 12 items which are said to identify three-character strengths Ho et al. (2016). A similar approach with a shorter version of the VIA Inventory, but including all 24 character strengths, would be beneficial for dyslexia populations. The sample size in the present study also limits the generalisability of our findings. Further studies need to be carried out with larger sample sizes [61-66].

\section{References}

1. Lawrence D (2009) Understanding dyslexia. Maidenhead: Open University Press.

2. Everatt J, Weeks S, Brooks P (2008) Profiles of strengths and weaknesses in dyslexia and other learning difficulties. Dyslexia 14(1): 16-41.

3. Eide B, Eide F (2011) The dyslexic advantage. Attree, Plume, New York, USA.

4. Attree EA, Turner MJ, Cowell N (2009) A virtual reality test identifies the visuospatial strengths of adolescents with dyslexia. Cyberpsychol Behaviour, 12(2): 163-168.

5. Geschwind N (1982) Why Orton was right. Annals of Dyslexia 32: 1330.

6. Karolyi, Winner, Gray, Sherman 2003 Dyslexia linked to talent: global visual-spatial ability. Brain Lang. 85(3):427-31.

7. Schneps, Matthews, Brockmole, Rose, Greenhill, et al. (2011) Dyslexia Linked to visual Strengths Useful in Astronomy. Bulletin of the American Astronomical Society, 43.

8. Wolff U, Lundberg I (2002) The prevalence of dyslexia among art students. Dyslexia 8(1): 34-42.

9. Everatt J, Steffert B, Smythe I (1999) An eye for the unusual: Creative thinking in dyslexics. Dyslexia 5(1): 28-46.

10. Wolf M (2008) Proust and the Squid. The story and science of the reading brain. Cambridge: Icon Books

11. Jackson L (2013, June) Dyslexia icon 013 (2004) Icon Magazine.

12. Schneps MH, Brockmole JR, Sonnert G, Pomplun M (2012) History of Reading Struggles Linked to Enhanced Learning in Low Spatial Frequency Scenes. PLoS ONE 7(4).

13. Dehaene S, Pegado F, Braga LW, Ventura P, Filho GN, et al. (2010) How Learning to Read Changes the Cortical Networks for Vision and Language. Science 330(6009): 1359-1364.

14. Franceschini S, Gori S, Ruffino M, Pedrolli K, Facoetti A (2012) A Causal Link between Visual Spatial Attention and Reading Acquisition. Current Biology 22(9): pp 814-819.

15. Geiger G, Lettvin JY (1987) Peripheral vision in persons with dyslexia. N Engl J Med 316(20): 1238-1243.

16. Geiger G, Cattaneo C, Galli R, Pozzoli U, Lorusso ML, et al. (2008) Wide and Diffuse Perceptual Modes Characterize Dyslexics in Vision and Audition. Perception 37(11): 1745-1764.
17. Hedenius M, Ullman MT, Alm P, Jennische M, Persson J (2013) Enhanced Recognition Memory after Incidental Encoding in Children with Developmental Dyslexia. PLOS ONE 8(5).

18. Miles TR, Thierry G, Roberts J, Schiffeldrin J (2006) Verbatim and gist recall of sentences by dyslexic and non-dyslexic adults. Dyslexia 12(3): 177-194.

19. Proctor C, Linley PA, Maltby J (2010) Very happy youths: Benefits of very high life satisfaction among Adolescents. Social Indicators Research 98: 519-532.

20. Park N, Peterson C, Seligman ME (2004) Strengths of Character and Wellbeing. Journal of Social and Clinical Psychology 23(5): pp 603-619

21. Park N \& Peterson C (2009). Strengths of character in schools. In R Gilman, ES Huebner \& MJ Furlong (Eds.), Handbook of positive psychology in schools (pp. 65-76). New York, NY, US: Routledge/Taylor \& Francis Group.

22. Tafti MA, Hameedy MA, Baghal NM (2009) Dyslexia, a deficit or a difference: Comparing the creativity and memory skills of dyslexic and nondyslexic students in Iran. Social Behavior and Personality: An International Journal 37(8): 1009-1016.

23. Davis RD, Braun E (1994) The gift of dyslexia: Why some of the smartest people can't read and how they can learn. New York Perigee Books, Penguin Group.

24.Jantzen C (2009). Dyslexia: Learning disorder or creative gift? Edinburgh: Floris Books.

25. Corlu M, Ozcan O, Korkmazlar U (2007) The Potential of Dyslexic Individuals in Communication Design Education. Behavioural Neurology,18(4): 217-223.

26. Cancer A, Manzoli S, Antonietti A (2016) The alleged link between creativity and dyslexia: Identifying the specific process in which dyslexic students excel. Cogent Psychology 3(1).

27. Patterson M (2011) The Paradox of Dyslexia: Slow Reading, Fast Thinking. The Nation's Oldest College Science Publication, Yale Scientific, USA.

28. Rooke M (2016) Creative, Successful, Dyslexic. Jessica Kingsley Publishers, London, UK.

29. Leveroy D (2013) Locating dyslexic performance: text, identity and creativity. Research in Drama Education: The Journal of Applied Theatre and Performance 18(4): 374-387.

30. Peterson C, Seligman MEP (2004) Character strengths and virtues: A classification and handbook. New York: Oxford University Press/ Washington.

31. Rowan L (2010) Learning with dyslexia in secondary school in New Zealand: What can we learn from students past experiences? Australian Journal of Learning Difficulties, 15(1): 71-79.

32. Burns E, Bell S (2010) Voices of teachers with dyslexia in Finnish and English further and higher educational settings. Teachers and Teaching 16(5): 529-543.

33. Griffiths S (2011) 'Being dyslexic doesn't make me less of a teacher'. School placement experiences of student teachers with dyslexia: strengths, challenges and a model for support. Journal of Research in Special Educational Needs, 12(2): 54-65.

34. Sanderson Mann J, Mccandless F (2006) Understanding dyslexia and nurse education in the clinical setting. Nurse Education in Practice, 6(3): 127-133.

35. Jennifer Poole (2003) Dyslexia: a wider view. The contribution of an ecological paradigm to current issues, Educational Research 45(2): 167-180

36. Vail P (1990) Gifts, Talents, and The Dyslexias: Wellsprings, Springboards, and Finding Foley's Rocks. Annals Of Dyslexia, 40: 3-17. 
37. Ghisi M, Bottesi G, Re AM, Cerea S, Mammarella (2016) Socioemotional Features and Resilience in Italian University Students with and without Dyslexia. Frontiers in Psychology, 7: 478.

38. Glazzard J, Dale K (2012) Trainee teachers with dyslexia: Personal narratives of resilience. Journal of Research in Special Educational Needs 13(1): 26-37.

39. Savolainen H, Ahonen T, Aro M, Tolvanen A, Holopainen L (2008) Reading comprehension, word reading and spelling as predictors of school achievement and choice of secondary education. Learning and Instruction 18(2): 201-210.

40. Stein DS, Blum NJ, Barbaresi WJ (2011) Developmental and behavioral disorders through the life span. Pediatrics, 128(2): 364-373.

41. Vogel SA, Murray C, Wren C, Adelman PB (2007) An Exploratory Analysis of Employment-Related Experiences of Educators with Learning Disabilities. Educational Considerations 34(2).

42. Reid G Came F, Price L (2008) Dyslexia: Workplace Issues. In Reid (ed) The Sage Handbook of Dyslexia. Abingdon, Routledge, UK.

43. Logan J (2009) Dyslexic entrepreneurs: the incidence; their coping strategies and their business skills, Dyslexia 15(4): pp. 328-346.

44. Fink RP (1998) Literacy development in successful men and women with dyslexia. Annals of Dyslexia, 48(1): pp 311-346.

45. Howard LM (1999) Education and clinical practice for the disabled student. Medical Teacher, 21(4): 428-429

46. Ferri BA, Keefe CH, Gregg N (2001) Teachers with learning disabilities: A view from both sides of the desk. Journal of Learning Disabilities 34(1): 22-32.

47. Collinson C, Penketh C (2010) Sit in the corner and don't eat the crayons': Postgraduates with dyslexia and the dominant 'lexic discourse. Disability \& Society 25(1): 7-19.

48. West TG (2009) In the mind's eye: Creative visual thinkers, gifted dyslexics and the rise of visual technologies (2nd ed.). Amherst, Prometheus Books, NY, USA.

49. Pink DH (2005) A whole new mind: Why right-brainers will rule the future: Riverhead Books, Newyork, USA.

50. Maccullagh L (2014) Participation and experiences of students with dyslexia in higher education: A literature review with an Australian focus. Australian Journal of Learning Difficulties 19(2): 93-111.

51. Koplewicz H, Grazer B (2012) Brian Grazer on Dyslexia: Support System. Child Mind Institute, New York, USA.

This work is licensed under Creative Commons Attribution 4.0 License DOI: 10.19080/GJIDD.2018.04.555648
52. Bell S (2009) Exploring support for dyslexic adults in the English workforce: Lessons learnt from the story of an adult dyslexia group. Support for Learning 24(2): 73-80.

53. Gladwell, M. (2014). David and Goliath. London: Allen Lane , Penguin Group.

54. Alexander-Passe, N (2015) Dyslexia and mental health. London, UK: Jessica Kingsley Publishers, London, UK.

55. Kirkby JR, Silvestri R, Allingham BH, Parrilla R, La Fave CB (2008) Learning strategies and study approaches of postsecondary students with dyslexia, J Learn Disabil 41(1): 85-96.

56. Madriaga M (2007) Enduring disablism: Students with dyslexia and their pathways into UK higher education and beyond. Disability \& Society 22(4): 399-412.

57. Gustems J, Calderon C (2013) Coping strategies and psychological well-being among teacher education students. European Journal of Psychology of Education 28(4): pp 1127-1140

58. Pirttimaa R, Takala M, Ladonlahti $T$ (2015) Students in higher education with reading and writing difficulties. Education Inquiry 6(1): 5-23.

59. Nicolson R (2015) Positive Dyslexia. Rodin Books, Sheffield, England.

60. Kannangara CS (2015) From Languishing Dyslexia to Thriving Dyslexia: Developing a New Conceptual Approach to Working with People with Dyslexia. Front Psychol 6: 1976.

61. Agahi A (2015) Investigating the strengths of dyslexia in successful adults and university students (Ph.D). University of Sheffield, England.

62. Jackson L (2013, June) Dyslexia icon 013 (2004) Icon Magazine, UK.

63. Kannangara CS, Griffiths D, Carson J, Munasinghe SK (2015) The relevance of cybernetics for a positive psychology approach to dyslexia. Kybernetes 8(9): 1284-1297

64. Maccullagh L, Bosanquet A, Badcock NA (2016). University Students with Dyslexia: A Qualitative Exploratory Study of Learning Practices, Challenges and Strategies. Dyslexia 23(1): 3-23

65. Price G (1997). The face of adult dyslexia in higher education. Dysfunctional organization: Intervention and identification. Paper presented at the $4^{\text {th }}$ International Conference of the British Dyslexia Association at University of York, UK.

66. Raskind MH, Goldberg RJ, Higgins EL, Herman KL (1999). Patterns of change and predictors of success in individuals with learning disabilities: Results from a twenty-year longitudinal study. Learning Disabilities Research and Practice 14(1): 35-49.

\section{Your next submission with Juniper Publishers will reach you the below assets}

- Quality Editorial service

- Swift Peer Review

- Reprints availability

- E-prints Service

- Manuscript Podcast for convenient understanding

- Global attainment for your research

- Manuscript accessibility in different formats

( Pdf, E-pub, Full Text, Audio)

- Unceasing customer service

Track the below URL for one-step submission

https://juniperpublishers.com/online-submission.php 